\title{
Outward Investments and Productivity Evidence from European Regions
}

\author{
Davide Castellani* Fabio Pieri ${ }^{\dagger}$
}

November 2014

\section{Online appendix}

\section{Empirical specification}

This section illustrates the rationale of the specification proposed in Equation 1 in the text and estimated in our empirical exercise. We start by assuming a linear relation between regional productivity and the stock of outward and inward FDI, allowing for the possibility of a time lag of $h$ periods.

$$
y_{i t}=\alpha+\beta k_{i t}+\gamma O U T_{i, \tau}^{\text {stock }}+\lambda I N W_{i, \tau}^{\text {stock }}+\eta_{i}+u_{i t}
$$

where $y_{i t}$ and $k_{i t}$ are the (log of) labour productivity and capital-labour ratio in region $i$ at time $t, O U T_{i, \tau}^{\text {stock }}$ and $I N W_{i, \tau}^{\text {stock }}$ are the stock of outward and inward FDI in region i at time $\tau=t-h, \eta_{i}$ is a regional fixed-effect, and $u_{i t}$ is the error term.

By taking differences over time we can eliminate the regional fixed effect. It is convenient to take differences between $t$ and $\tau$, since it yields an equation where there is no overlap between the periods used to compute the growth rate of productivity and the change in the stock of outward and inward FDI. We denote this difference as $\Delta_{\text {start }}^{\text {end }}$. The equation in differences looks as follows:

$$
\Delta_{\tau}^{t} y_{i t}=\beta \Delta_{\tau}^{t} k_{i t}+\gamma \Delta_{\tau-h}^{\tau} O U T_{i, \tau}^{s t o c k}+\lambda \Delta_{\tau-h}^{\tau} I N W_{i, \tau}^{\text {stock }}+\Delta_{\tau}^{t} u_{i t}
$$

Due to the lack of information on FDI stocks, we need to assume that the number of outgoing and incoming investments projects, as recorded by fDi Markets, from/into each region over the period between $\tau-h$ and $\tau$-which we denote as $O U T_{i, \tau-h \rightarrow \tau}$ and $I N W_{i, \tau-h \rightarrow \tau}$ - can be a proxy for the change of the stocks of outward and inward FDIs, respectively, over the same period. This assumption is subject to two major criticisms. First, we do not allow any depreciation in the FDI stock. Second, we assume that all

*Department of Economics, University of Perugia, Via A. Pascoli 20, 06123 Perugia (Italy); Centro Studi Luca d'Agliano, Milan (Italy); Centre for Innovation, Research and Competence in the Learning Economy (CIRCLE), Lund (Sweden); davide.castellani@unipg.it

${ }^{\dagger}$ Corresponding author: Departamento de Economia Aplicada, Universitat de Valencia, Avinguda dels Tarongers s/n, 46022, Valencia (Spain); fabio.pieri@uv.es 
investments projects are of the same size, in terms of invested assets. As it is shown in Table 1, the correlation between FDI flows and the number of projects recorded by fDi Markets at the country level is remarkably high, so we believe the assumption may hold. Then, our specification becomes:

$$
\Delta_{\tau}^{t} y_{i t}=\beta \Delta_{\tau}^{t} k_{i t}+\gamma O U T_{i, \tau-h \rightarrow \tau}+\lambda I N W_{i, \tau-h \rightarrow \tau}+\Delta_{\tau}^{t} u_{i t}
$$

In order to make results comparable when using different $h$ (as in the section reporting the performed robustness checks), we can take averages of $\Delta_{\tau}^{t} y_{i t}, \Delta_{\tau}^{t} k_{i t}, O U T_{i, \tau \rightarrow t}$ and $I N W_{i, \tau \rightarrow t}$. We denote the averaged variables with an overline. As discussed in Section 3 in the text, we can augment Equation 3 with a constant $(\alpha)$, a vector of country fixed effect $\left(\eta_{j}\right)$ and of regional characteristics at the beginning of the period $\left(\mathbf{z}_{i, \tau}\right)$.

$$
\Delta_{\tau}^{t} \bar{y}_{i t}=\alpha+\beta \Delta_{\tau}^{t} \bar{k}_{i t}+\gamma{\overline{O U T_{i, \tau-h \rightarrow \tau}}}+\lambda \overline{I N W}_{i, \tau-h \rightarrow \tau}+\eta_{j}+\delta \mathbf{z}_{i, \tau}+\Delta_{\tau}^{t} u_{i t}
$$

For $h=4$, given the time structure of our data, we are left with $t=2011, \tau=2007$ and $\tau-h=2003$, which then yields Equation 1 in the text:

$\Delta \bar{y}_{i j, 2007-11}=\alpha+\beta \Delta \bar{k}_{i j, 2007-11}+\gamma \overline{O U T}_{i j, 2003-07}+\lambda \overline{I N W}_{i j, 2003-07}+\delta \mathbf{z}_{i j, 2007}+\eta_{j}+\epsilon_{i j, 2007-11}$.

\section{Physical capital-labor ratio}

We have included a physical capital deepening term $\left(\Delta k_{i j, 2007-11}\right)$ in Equation 1 in the text as the rate of change of the physical capital-labor ratio, in order to control for changes in regional factor shares. The physical capital-labor ratio has been computed as the ratio of the regional physical capital stock to regional employment (in thousands of employees). The physical capital stock at the regional level, has been obtained applying the perpetual inventory method (PIM) to the series of gross fixed capital formation (GFCF) in the region (at constant 2005 prices in millions of euro) contained in the ERD database (last release, 2013). We followed the methodology proposed by HALL and MAIRESSE (1995), and the physical capital stock at the beginning of the first year has been defined as below:

$$
K_{i j, t=1}=\frac{I_{i j, t=1}}{g_{i j}+\delta}
$$

where $I_{i j, t=1}$ is the value of GFCF observed in region $i$ in the first year of the series 1 , $g_{i j}$ is the rate of growth of GFCF in the region from 1995-2002, and $\delta$ is depreciation rate which has been set equal to $7.5 \%$. Physical capital stock in the second year and onward has been computed using the following formula:

$$
K_{i j, t}=(1-\delta) \cdot K_{i j, t-1}+I_{i j, t} .
$$

The variable has been included in growth rates in the econometric analysis, $\Delta k_{i j, 2007-11}$.

\footnotetext{
${ }^{1}$ We start computing the physical capital stock series at 1995, even if in the econometric analysis we use the values from 2007 to 2011. The main motivation relates to the possibility of resting on more reliable values for the physical capital stock calculated as in the Equation 6 .

${ }^{2}$ As robustness checks we also computed the physical capital stock assuming depreciation rate of $5 \%$ and $10 \%$, and we did not register significantly different results.
} 


\section{Other regional characteristics}

This paragraph provides details on how some of the additional regional characteristics contained in the $\mathbf{z}_{i j, 2007}$ vector - i.e. the level of human capital, the stock of technological capital, the regional industrial mix and its degree of concentration/diversification, the regional employment density - have been built.

- The endowment of human capital $\left(H C A P_{i j, 2007}\right)$ has been proxied by the share of population aged 25 or more (in thousands of people) with tertiary-type education degree (ISCED 5-6) in each region. Information comes from the EURD dabase, maintained by Eurostat. The value has been included in log in the econometric analysis, $h c a p_{i j, 2007}$.

- The stock of technological capital $\left(\right.$ tech $\left._{i j, 2007}\right)$ has been proxied by the ratio of the stock of patent applications to the total population (in thousands of people) in the region. The stock - recovered using information on the number of patent applications from each European region to the European Patent Office (EPO), which is available in the EURD database, maintained by Eurostat ${ }^{3}-$ has been computed as the sum of the patent applications in all sectors in the previous five years:

$$
\mathrm{TECH}_{i j, 2007}=\sum_{t=2002}^{2007} \operatorname{PATAPP} P_{i j, t} .
$$

The ratio has been included in log in the econometric analysis, $t e c h_{i j, 2007}$.

- We have controlled for the degree of concentration/diversification of the regional industrial mix. Following the literature (see CingANO and SCHIVARDI, 2004, among others), we have used the Herfindahl-Hirschman index computed as follows:

$$
H H I_{i j, 2007}=\sum_{s} S H_{s i j, 2007}^{2}=\sum_{s}\left(\frac{\text { Employment }_{s i j, 2007}}{\text { Employment }_{i j, 2007}}\right)^{2},
$$

where $S H_{s i j, 2007}$ are the employment shares in five broad sectors ' $s$ ' of the regional economy: (1) agriculture, hunting, forestry and fishing; (2) industry (energy and manufacturing); (3) construction; (4) non-market services; (5) distribution, transportation and commercial services; (6) financial services and other services. The $H H I$ index is equal to ' 1 ' for regions with all their employees concentrated in one sector and tends to ' 0 ' in the case of more diversified regional structures. The $H H I_{i j, 2007}$ enters in log in the econometric analysis, $h h i_{i j, 2007}$.

- We calculate a measure of employment density DENSITY $Y_{i j, 2007}$ as the ratio between total regional employment (in thousands of employees) over regional area (in square kilometers). DENSITY ${ }_{i j, 2007}$ enters in log in the econometric analysis, density $y_{i j, 2007}$.

\footnotetext{
${ }^{3}$ Data on patent applications are regionalized on the basis of investors' residence: in the case of multiple investors proportional quotas have been attributed to each region.
} 
- We have taken account of the regional industrial structure by introducing the share of employment in three broad sectors of the economy, i.e. Agriculture, Industry and Services. Each share has been computed in the following way:

$$
\text { share }_{i j, 2007}^{s *}=\frac{\text { Employment }_{s * i j, 2007}}{\text { Employment }_{i j, 2007}}
$$

where where $s *=\{A G R, I N D, S E R V\}$ and Employment Ej, $2007_{\text {and }}$ Employment ${ }_{s * i j, 2007}$ denote, respectively, total employment of the region $i$ in country $j$ (thousands of employees) and total employment in the $s * t h$ sector of the regional economy (thousands of employees). 


\section{Correlation matrix}

Table 1 provides the matrix of Pearson's correlation coefficients among the variables included in the econometric analysis.

\section{List of regions}

This paragraph provides the list of NUTS 2 regions which has been considered in the econometric analysis (Table 2). 


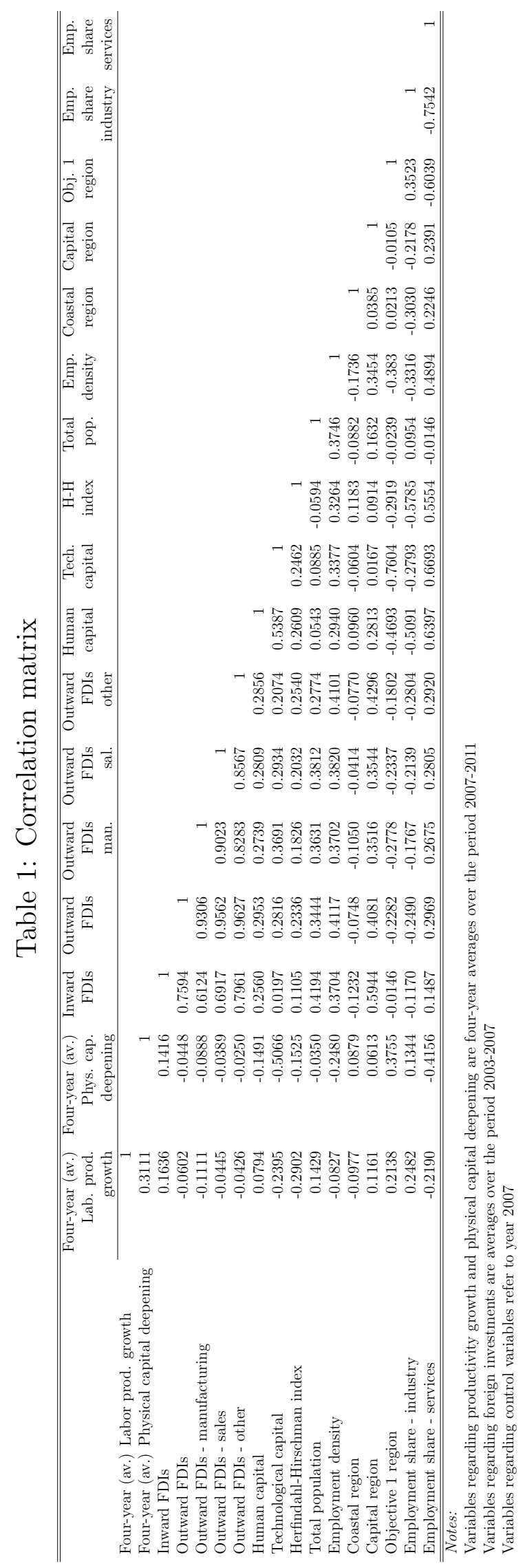




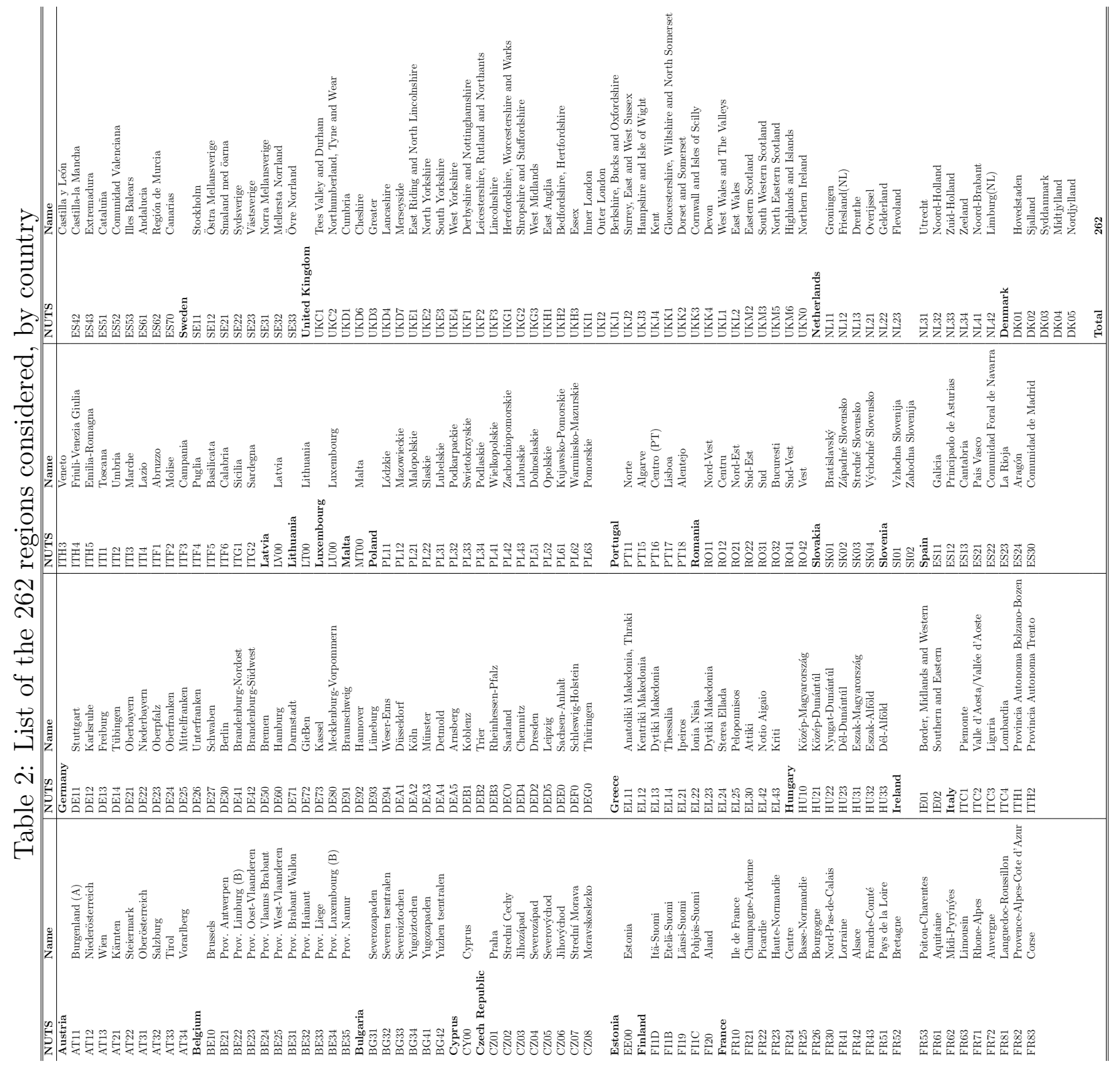




\section{References}

Cingano F. and Schivardi F. (2004) Identifying the sources of local productivity growth, Journal of the European Economic Association 2(4), 720-742.

Hall B. H. and Mairesse J. (1995) Exploring the relationship between r\&d and productivity in french manufacturing firms, Journal of Econometrics 65, 263-293. 